\title{
Preparation of Carbon Quantum Dots from Corn Straw and their Application in $\mathrm{Cu}^{2+}$ Detection
}

\begin{abstract}
Jiliang Yang, ${ }^{\mathrm{a}}$ Zijiao Guo, ${ }^{\mathrm{b}}$ and Xiantian Yue ${ }^{\mathrm{a}, *}$
Water-soluble carbon quantum dots were hydrothermally produced using corn straw as the starting material and nitric acid solution as solvent, then they were introduced as fluorescent probes for the detection of $\mathrm{Cu}^{2+}$. Highresolution transmission electron microscopy and X-ray diffraction showed that the carbon quantum dots were spherical amorphous particles with a diameter of $5 \mathrm{~nm}$. The surface functional groups of carbon quantum dots were observed via Fourier transform infrared spectrometry and X-ray photoelectron spectroscopy. A new approach for $\mathrm{Cu}^{2+}$ detection was designed using carbon quantum dots based on fluorescence quenching. Linear relationships between the fluorescence variation and the $\mathrm{Cu}^{2+}$ level (1 $\mathrm{mg} \cdot \mathrm{L}^{-1}$ to $20 \mathrm{mg} \cdot \mathrm{L}^{-1}$ and $20 \mathrm{mg} \cdot \mathrm{L}^{-1}$ to $500 \mathrm{mg} \cdot \mathrm{L}^{-1}$ ) were obtained, with coefficients of determination of 0.9960 and 0.9923 , respectively. The $\mathrm{Cu}^{2+}$ detection limit was $4.26 \mathrm{mg} \cdot \mathrm{L}^{-1}$. The probable quenching principle between $\mathrm{Cu}^{2+}$ and the carbon quantum dots was attributed to charge transfer.
\end{abstract}

DOI: 10.15376/biores.17.1.604-615

Keywords: Carbon dots; Corn straw; Copper ions; Detection

Contact information: a: College of Chemistry and Material Engineering, Chaohu University, Hefei 238024 China; b: School of Textiles and Fashion, Shanghai University of Engineering Science, Shanghai 201620 China; *Corresponding author: yuefeiyxt@aliyun.com

\section{INTRODUCTION}

Carbon quantum dots (CQDs) are one of the most attractive fluorescent nanomaterials, given they have the following advantages: low toxicity, high watersolubility, favorable biocompatibility, excellent electronic properties, high photostability, and easy surface functionalization (Xu et al. 2015; Yu et al. 2015; Su et al. 2018; Xie et al. 2019). For this reason, CQDs are successfully applied in many fields, including fluorescent ink (Li et al. 2018), solar cells (Briscoe et al. 2015), cell imaging (Huang et al. 2019), sensors (Yang et al.2019), photocatalysis (Cao et al. 2011), and drug delivery (Feng et al. 2016). The synthesis method of carbon quantum dots can be roughly divided into topdown methods (e.g., arc discharge and laser burning) and bottom-up methods (e.g., hydrothermal, microwave digestion and ultrasonic oscillation). Many efforts have been made to synthesize CQDs using a variety of chemical precursors with different methods, including plasma discharge (Ke et al. 2018), laser ablation (Sidorov et al. 2018), microwave heating (Medeiros et al. 2019), chemical oxidation (Qiao et al. 2010), arcdischarge (Zhu et al. 2013), and electrochemical synthesis (Muthusankar et al. 2018). However, most of the above methods are unlikely to be extended because of toxic raw materials, complex operation processes, high costs, or severe synthetic conditions. In terms of environmental protection, the synthesis of CQDs from low-cost and nontoxic raw materials via an environmentally friendly route is a major issue. 
In recent decades, biomass has been considered an important renewable resource and has been used to successfully prepare various materials. Several studies have employed biomass resources as starting materials to fabricate CQDs, e.g., highland barley (Xie et al. 2019), milk (Su et al. 2018), potatoes (Xu et al. 2015), oatmeal (Yu et al. 2015), hong cai tai (Li et al. 2018), flowers (Huang et al. 2019), plant leaves (Zhu et al. 2013), soybeans (Hu et al. 2019), and Dunaliella salina (Singh et al. 2019). However, most of these CQDs were synthesized from edible and usable materials, causing a waste of resources. Searching for new carbon sources for the easy utilization, extensive application, and green production of CQDs is urgently needed.

Agricultural straws, e.g., wheat straw and corn straw, which are major crop residues, consist of $28 \%$ to $36 \%$ cellulose, $23 \%$ to $28 \%$ hemicellulose, and $12 \%$ to $16 \%$ lignin (Jin et al. 2017). So far, nearly $27.1 \%$ of agricultural straw is used as roughage in livestock feed rations, approximately $14.1 \%$ is buried in soil for use as fertilizer, and approximately $32.3 \%$ is used as fuels, which causes air pollution and contributes to the greenhouse effect (Yuan et al. 2015). Hence, a new value-added strategy for the effective recycling of theses agricultural wastes is highly desirable.

Corn straw is one of the most common agricultural wastes in China. A high-value use of corn straw can relieve energy insecurity and reduce ecological pollution. Herein, corn straw was chosen as the model agricultural waste for CQD synthesis, providing a diverse use of corn straw as well as achieving a facile one-pot preparation of biomassbased CQDs. Moreover, when carbon quantum dots are in contact with metal ions, the phenomenon of fluorescence quenching occurs due to energy transfer, charge transfer and surface adsorption. Based on fluorescence quenching, the CQDs were applied for the highly selective and sensitive detection of $\mathrm{Cu}^{2+}$. Compared with other detection methods, the fluorescence detection method has the advantages of simple operation, no expensive equipment, and low price.

\section{EXPERIMENTAL}

\section{Materials}

Corn straw was collected from wheat fields in Anhui, China. The chemical reagents were made by Xilong Chemical Reagent Co., Ltd. (Guangdong, China). All reagents were analytically pure and used as received.

\section{Preparation of the Carbon Quantum Dots (CQDs)}

Corn straw was crushed to a size of approximately 60 mesh for the hydrothermal preparation of CQDs. Typically, $1.0 \mathrm{~g}$ of corn straw was added to $30 \mathrm{~mL}$ of a $0.2 \mathrm{~mol} \cdot \mathrm{L}^{-1}$ $\mathrm{HNO}_{3}$ solution and heated in a water bath at a temperature of $50{ }^{\circ} \mathrm{C}$ for $4 \mathrm{~h}$. Then, the mixture was moved into a $50 \mathrm{~mL}$ Teflon-lined autoclave and heated at a temperature of $180{ }^{\circ} \mathrm{C}$ for $13 \mathrm{~h}$. The product was harvested via centrifugation at $8000 \mathrm{rpm}$ for $10 \mathrm{~min}$ to remove the unreacted raw materials and large carbon products before finally being freezedried under vacuum.

\section{Characterization}

First, the $100 \mathrm{mg} \cdot \mathrm{L}^{-1}$ CQDs solution was loaded on a 300-mesh copper grid and dried at room temperature, then the CQDs were observed by a JEM-2100F transmission electron microscope (TEM) (JEOL, Tokyo, Japan). The functional groups of the CQDs 
were investigated using a FTIR-650 Fourier transform infrared spectrometer (FTIR) (Gangdong Science \& Technology Development Co., China). The Kratos Axis Ultra HASVision X-ray photoelectron spectroscope (XPS) was run under a monochromatized Al K $\alpha$ radiation. Additional instruments included an F96Pro fluorescence emission spectrophotometer (Lengguang Science \& Technology Development Co., China), an ESCALAB250 electron spectrometer (Thermo Electron, Waltham, MA), a D/Max-2000 X-ray diffractometer (XRD) (Rigaku Co., Tokyo, Japan), and an ultraviolet-visible spectrophotometer (UV1750, Shimadzu, Kyoto, Japan).

\section{Fluorescence Quantum Yield (QY) Measurement}

The fluorescence quantum yield (QY) of the CQDs was estimated with quinine sulfate as the reference (a QY of 0.54). The quinine sulfate and CQDs were diluted with $0.1 \mathrm{~mol} \cdot \mathrm{L}^{-1} \mathrm{H}_{2} \mathrm{SO}_{4}$ (a refractive index $(\eta)$ of 1.33 ) and ultrapure water (a $\eta$ of 1.33 ), respectively, to different levels. The relative fluorescence QY of the CQDs was computed according to Eq. 1,

$$
Q Y=Q Y_{R} \cdot\left(\frac{K}{K_{R}}\right) \cdot\left(\frac{\eta}{\eta_{R}}\right)^{2}
$$

where the subscript $R$ is the reference, and $K$ is the slope of the linear curve of the fluorescence integrated area against the absorbance (Gedda et al. 2016; Li et al. 2018).

\section{Detection of $\mathrm{Cu}^{2+}$}

In a typical $\mathrm{Cu}^{2+}$ detection experiment, $2 \mathrm{~mL}$ of a $500 \mathrm{mg} \cdot \mathrm{L}^{-1} \mathrm{CQD}$ solution was first added to a cuvette, and then $2 \mathrm{~mL}$ of a $\mathrm{Cu}^{2+}$ aqueous solution at a given concentration was injected. The resulting mixed solution was diluted to $10 \mathrm{~mL}$ with a phosphate buffer solution (PBS), with a $\mathrm{pH}$ of 6.7, and evenly mixed. The mixture was allowed to sit at ambient temperature $120 \mathrm{~min}$ to balance, and finally the FL intensity was measured under fluorescence excitation at $365 \mathrm{~nm}$. The reaction time, volume of CQDs, type of buffer solution, $\mathrm{pH}$ effect, sensitivity, and selectivity were measured in triplicate for all experiments.

\section{RESULTS AND DISCUSSION}

\section{Characterization of the Carbon Quantum Dots (CQDs)}

The UV-vis spectrum and fluorescence spectroscopy are shown in Fig. 1. The CQDs solution is a dark yellow under normal light and a blue-green under a $365 \mathrm{~nm} \mathrm{UV}$ lamp (as shown in the Fig. 1 inset). The UV-vis spectrum of CQDs shows a sharp absorption peak at approximately $300 \mathrm{~nm}$, which is ascribed to the $\pi \rightarrow \pi^{*}$ electron migration from the $\mathrm{sp}^{2}$ hybridized clusters (Gedda et al. 2016; Yuan et al. 2018; Qi et al. 2019; Ren et al. 2019). The emission peaks of the CQDs are excitation-dependent with the excitation wavelength increasing from 310 to $390 \mathrm{~nm}$, and the strongest emission occurs under excitation at $350 \mathrm{~nm}$, with a peak at $440 \mathrm{~nm}$. As the excitation wavelength increased from 350 to $390 \mathrm{~nm}$, the maximum emission peak right-shifted from 433 to $460 \mathrm{~nm}$ together with the decreased emission intensity. This unique phenomenon can be attributed to the optical selection of different defect states on the surface of the CQDs (Su et al. 2018). The quantum yield of the CQDs was measured to be $4.64 \%$. 


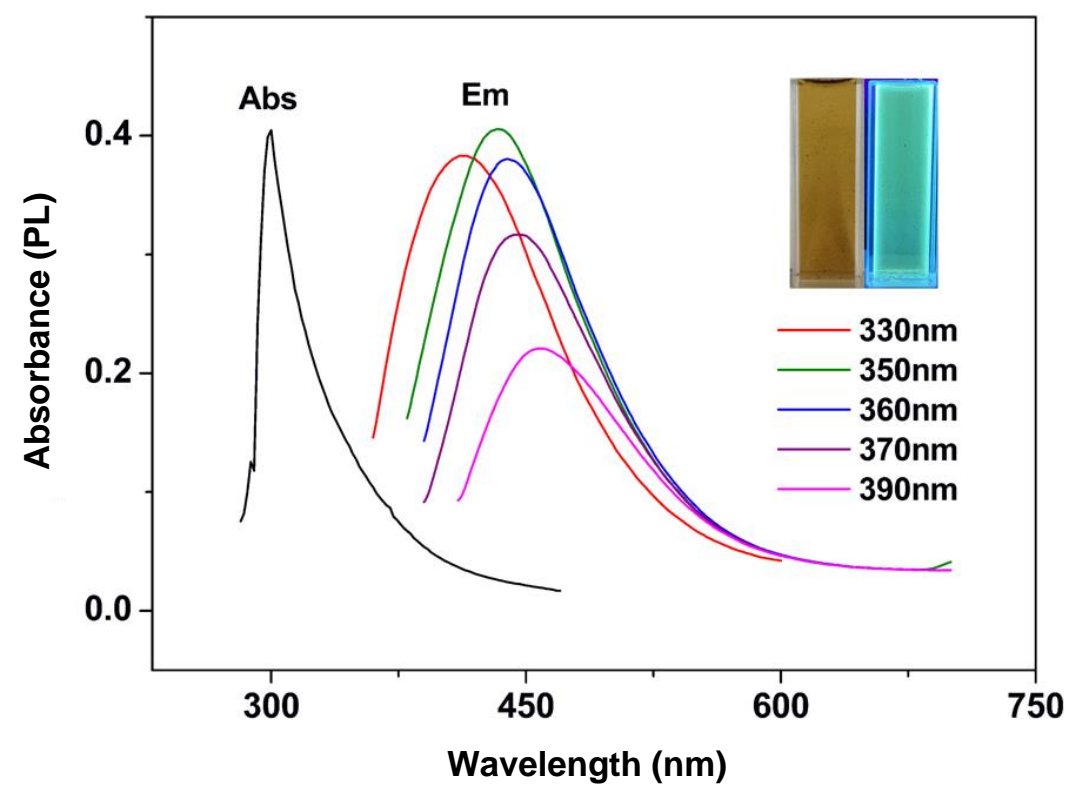

Fig. 1. Absorption and fluorescence spectrum of the CQDs solution. The inset images are the corresponding fluorescence images under visible light and UV light ( $365 \mathrm{~nm}$ ).

The morphology of the CQDs was observed via high-resolution transmission electron microscopy (HRTEM). As shown in Fig. 2, most of the particles were spherically shaped and monodispersed, without apparent aggregation, and their sizes were approximately $5 \mathrm{~nm}$. Figure 2 reveals the crystallinity of the CQDs with a lattice fringe of $0.208 \mathrm{~nm}$, suggesting that the CQDs are composed of $\mathrm{sp}^{2}$ graphitic carbons, $\mathrm{sp}^{3}$ carbon defects, and surface functional groups, e.g., $-\mathrm{OH}, \mathrm{C}=\mathrm{O}$, and $-\mathrm{NH}$ (Zhu et al. 2013). The XRD pattern of the CQDs (Fig. 3) displays a strong peak at $c a .24^{\circ}$, which reveals the amorphous carbon structure of the CQDs (Gedda et al. 2016).

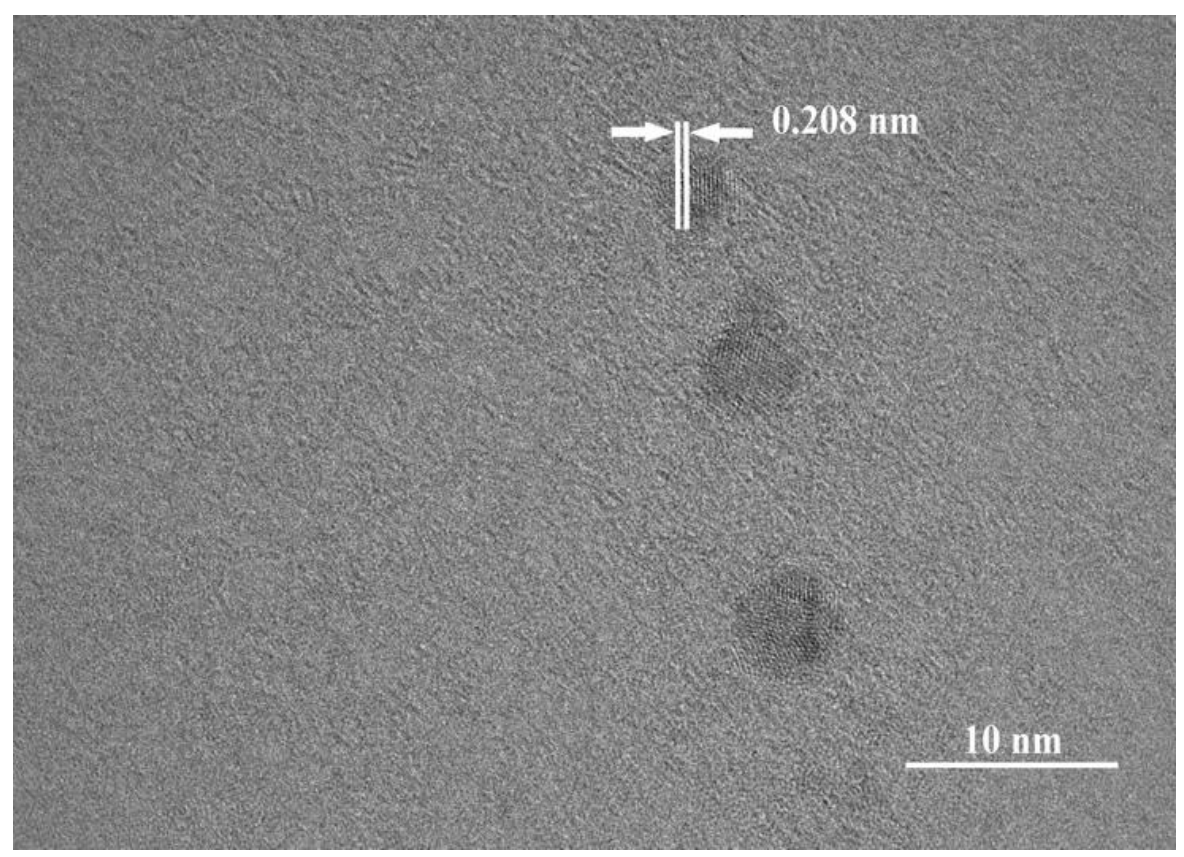

Fig. 2. HRTEM image of the CQDs 


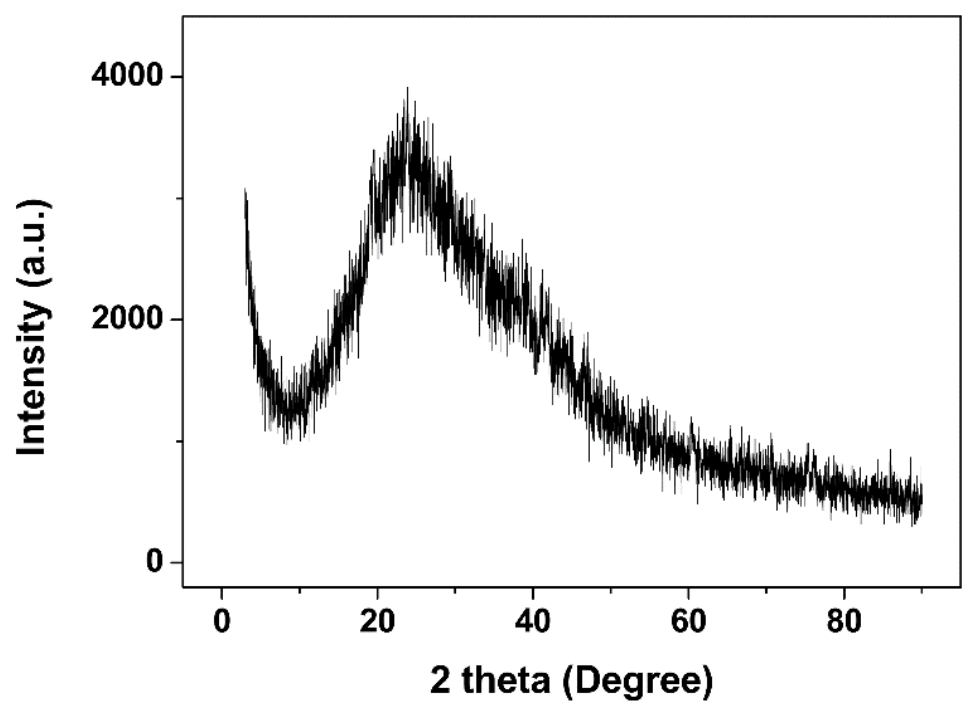

Fig. 3. XRD spectra of the CQDs

The FTIR and XPS spectra were also explored to observe the surface functional groups of the CQDs. The FTIR spectrum (Fig. 4) shows bands at 3180 and $3405 \mathrm{~cm}^{-1}$ caused by the $\mathrm{O}-\mathrm{H}$ and $\mathrm{N}-\mathrm{H}$ stretching vibrations of the amine groups (Yu et al. 2015). The characteristic peaks at 1610 and $1710 \mathrm{~cm}^{-1}$ represent $\mathrm{C}=\mathrm{C}$ and $\mathrm{C}=\mathrm{O}$, respectively (Yan et al. 2016). The peak at $1384 \mathrm{~cm}^{-1}$ is assigned to $\mathrm{C}-\mathrm{N}$ (Hu et al. 2019; Liu et al. 2019). The peaks at approximately $1175 \mathrm{~cm}^{-1}$ and $1090 \mathrm{~cm}^{-1}$ are ascribed to C-O-C and C-O stretching, respectively (Zhu et al. 2013; Yu et al. 2015; Qi et al. 2019). The peak at $834 \mathrm{~cm}^{-1}$ is due to the aromatic C-H stretching vibration (Jing et al. 2019; Ren et al. 2019). Furthermore, the peak at approximately $640 \mathrm{~cm}^{-1}$ is assigned to the $\mathrm{CH}_{2}$ stretching (Yang et al. 2018). These results were further verified via XPS.

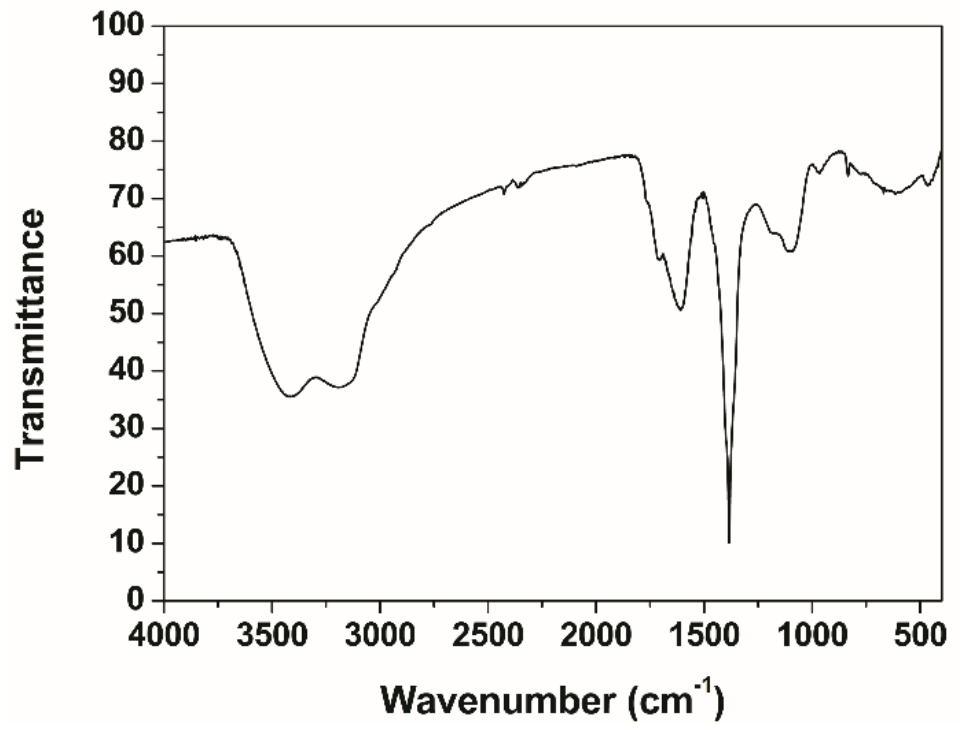

Fig. 4. FTIR spectra of CQDs

The peaks at $296.43 \mathrm{eV}, 410.43 \mathrm{eV}$, and $545.43 \mathrm{eV}$ correspond to the $\mathrm{C} 1 \mathrm{~s}, \mathrm{~N} 1 \mathrm{~s}$ and O1s electrons, respectively (Fig. 5a). The elemental composition of the CQDs is C 52.85\%, $\mathrm{N} 4.49 \%$, and $\mathrm{O} 42.66 \%$. The peaks in the high-resolution $\mathrm{C} 1 \mathrm{~s}$ spectrum (Fig. 5b) at 284.6 
$\mathrm{eV}, 286.7 \mathrm{eV}$, and $288.7 \mathrm{eV}$ are attributed to $\mathrm{C}-\mathrm{C}, \mathrm{C}-\mathrm{O}$, and $\mathrm{C}=\mathrm{O} / \mathrm{C}=\mathrm{N}$, respectively. The high-resolution N1s spectrum (Fig. 5c) demonstrates three peaks at 399.8, 400.5, and 401.8 $\mathrm{eV}$, which confirm the presence of $\mathrm{C}-\mathrm{N}-\mathrm{C}, \mathrm{N}-\mathrm{H}$, and $\mathrm{C}_{3}-\mathrm{N}$, respectively. On the $\mathrm{O} 1 \mathrm{~s}$ spectrum (Fig. 5d), the two binding energy peaks at approximately $531.9 \mathrm{eV}$ and $532.2 \mathrm{eV}$ represent $\mathrm{C}-\mathrm{OH} / \mathrm{C}=\mathrm{O}$ and $\mathrm{C}-\mathrm{O}-\mathrm{C}$, respectively.
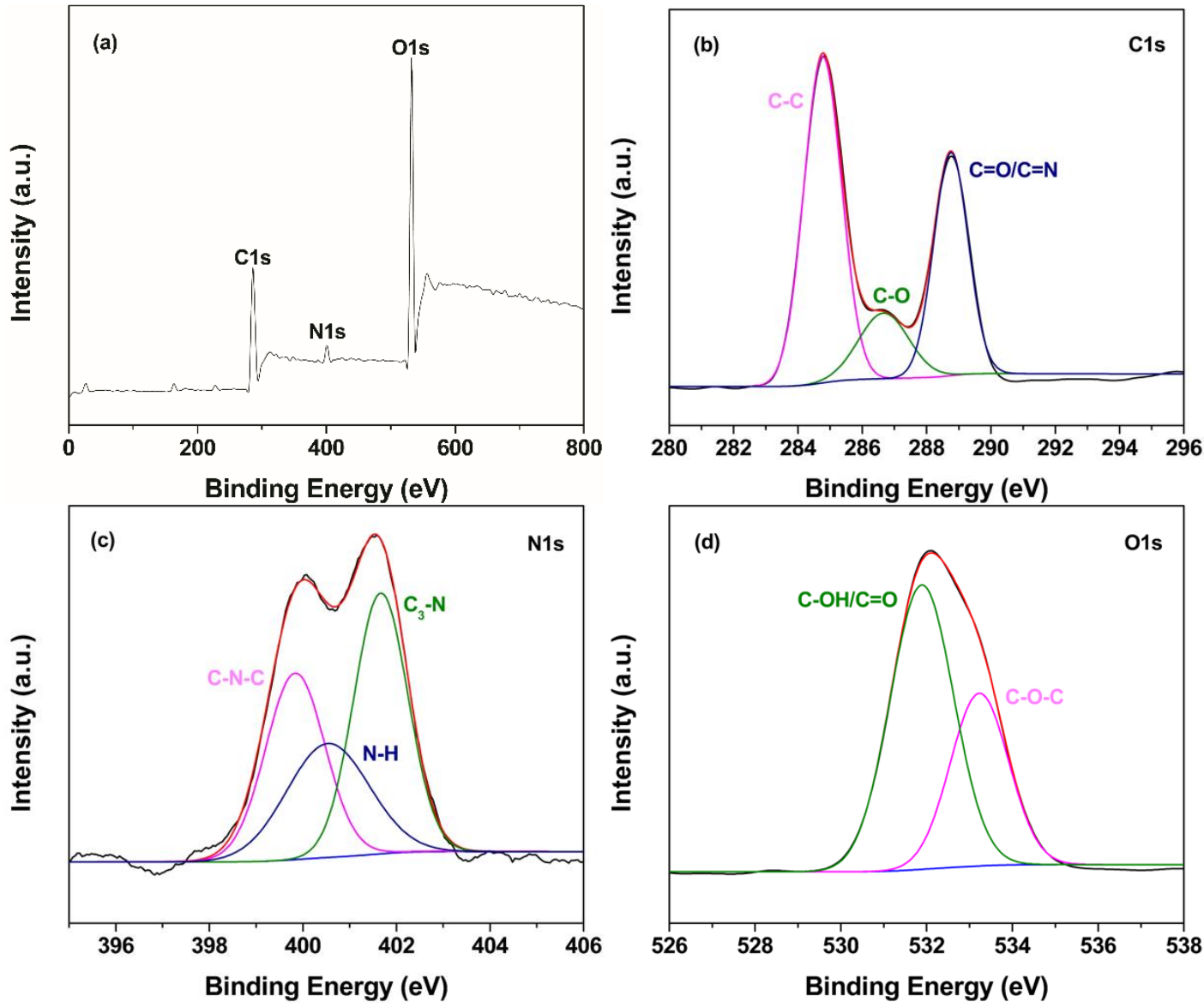

Fig. 5. XPS full spectrum of the CQDs (a) and the high-resolution C1s (b), N1s (c), and O1s (d) spectra of the CQDs

\section{Optimization of the Detection Conditions}

Reaction time

The ideal time scale complexation between the CQDs and $\mathrm{Cu}^{2+}$ was explored. First, $2 \mathrm{~mL}$ of a $500 \mathrm{mg} \cdot \mathrm{L}^{-1} \mathrm{CQD}$ solution and $2 \mathrm{~mL}$ of a $50 \mathrm{mg} \cdot \mathrm{L}^{-1} \mathrm{Cu}^{2+}$ aqueous solution were mixed and diluted to $10 \mathrm{~mL}$ with distilled water. After that, the time-dependent $\mathrm{Cu}^{2+}$-CQDs fluorescence intensity curve was recorded (Fig. 6a). The results indicated that the fluorescence intensity of the CQDs weakened with time, and stabilized after $120 \mathrm{~min}$. The ideal reaction time was set to $120 \mathrm{~min}$ for further experiments.

Volume of the carbon quantum dots (CQDs) solution

The CQDs content has a major role in deciding the fluorescence intensity and quenching in a system. Thus, a series of experiments with different CQDs solution volumes were carried out to determine the appropriate volume. The fluorescence quenching efficiency can be calculated according to Eq. 2, 


$$
\frac{F_{0}}{F}=1+K_{s v}\left[C u^{2+}\right]
$$

where $F_{0}$ and $F$ correspond to the fluorescence intensities of the CQDs before and after adding $\mathrm{Cu}^{2+}$, respectively, and $K_{\mathrm{SV}}$ is the Stern-Volmer quenching constant (Yang et al. 2019). The fluorescence intensity was enhanced as the volume of the CQDs solution increased. The quenching rate $\left(F_{0}-F\right) / F_{0}$ maximized at a volume of $2 \mathrm{~mL}$ (as shown in Fig. $6 b)$, which was selected as the appropriate CQDs solution volume.

The effect of the buffer solution and $\mathrm{pH}$ on the fluorescence sensing system

The buffer solution and the $\mathrm{pH}$ are two essential factors that can affect the sensing system. Thus, a series of experiments with different buffer solutions and $\mathrm{pHs}$ were investigated to identify the appropriate buffer solution and $\mathrm{pH}$ (Fig. 6c and 6d). At a pH of approximately 7.4 for all solvents, the fluorescence quenching rate $\left.\left(F_{0}-F\right) / F_{0}\right)$ was maximized when the solvent was PBS, which was chosen for the detection system (Fig. 6c). The effect of the $\mathrm{pH}$ was also tested at a range of 5.9 to 8.0 in PBS (Fig. 6d). It was found that the $\left(F_{0}-F\right) / F_{0}$ was maximized at a $\mathrm{pH}$ of 6.7 , which was set as the appropriate $\mathrm{pH}$.
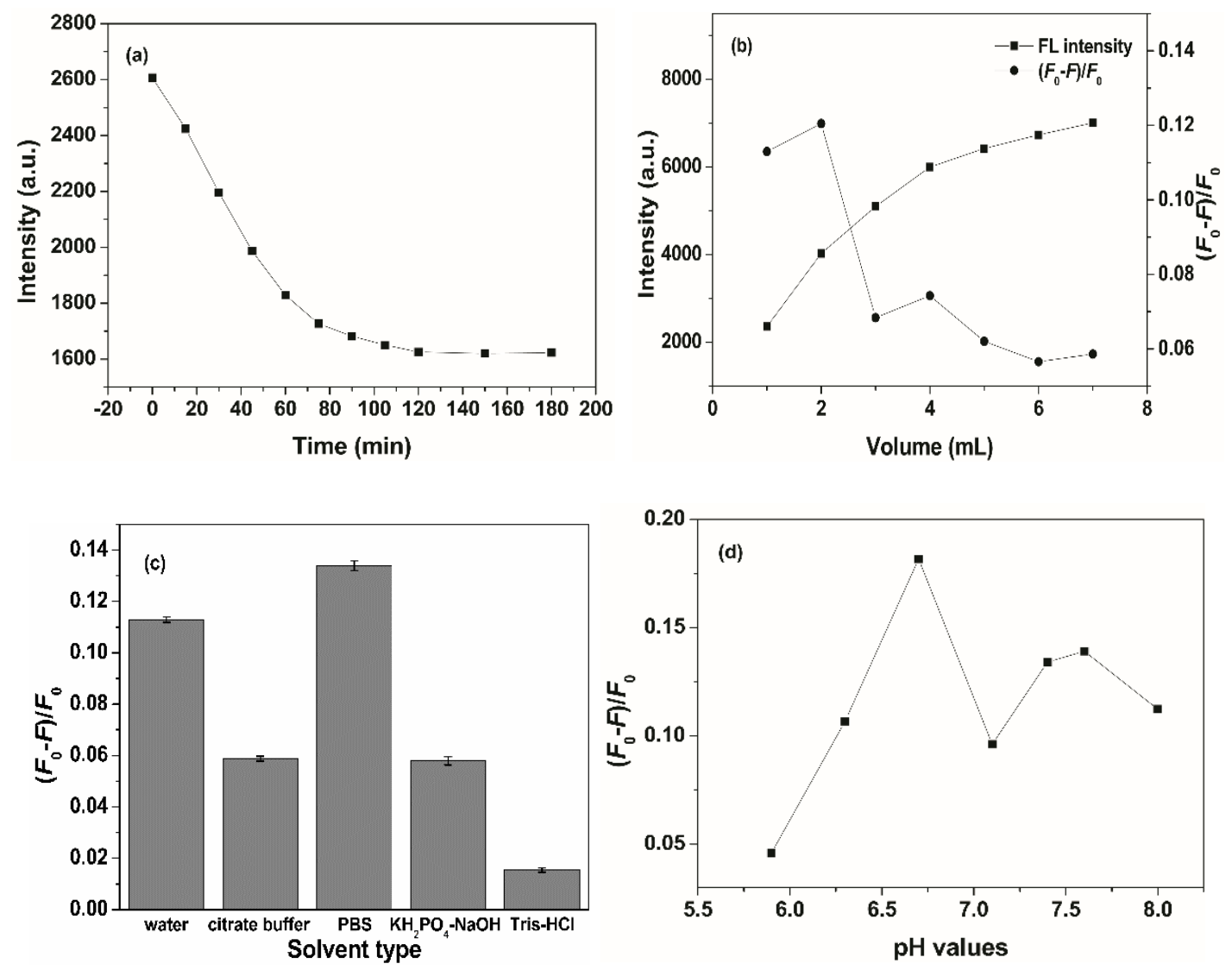

Fig. 6. (a) The effect of reaction time on the fluorescence intensity of the system; (b) the effect of different CQDs solution volumes on the fluorescence intensity and quenching rate; (c) the effect of the buffer solution on the fluorescence sensing system; and (d) the effect of the $\mathrm{pH}$ on fluorescence sensing system 


\section{Detection of $\mathrm{Cu}^{2+}$}

Under optimal settings, the $\mathrm{Cu}^{2+}$ solutions at given concentrations (each $2 \mathrm{~mL}$ ) were added to $2 \mathrm{~mL}$ of the $500 \mathrm{mg} \cdot \mathrm{L}^{-1} \mathrm{CQDs}$ solution, and then the above mixture solutions were all diluted to $10 \mathrm{~mL}$ with PBS (at a $\mathrm{pH}$ of 6.7). After the reactions proceeded at ambient temperature for $120 \mathrm{~min}$, the fluorescence intensities were recorded under excitation at $365 \mathrm{~nm}$. The fluorescence intensity of the CQDs decreased as the $\mathrm{Cu}^{2+}$ concentration increased (Fig. 7). Approximately linear relationships can be found at $\mathrm{Cu}^{2+}$ concentration of 1 to $20 \mathrm{mg} \cdot \mathrm{L}^{-1}$ and 20 to $500 \mathrm{mg} \cdot \mathrm{L}^{-1}$, with corresponding calibration curves of $F_{0} / F=0.0078\left[\mathrm{Cu}^{2+}\right]+1.0104\left(\mathrm{R}^{2}=0.9960\right)$ and $F_{0} / F=0.0002\left[\mathrm{Cu}^{2+}\right]+1.1692$ $\left(\mathrm{R}^{2}=0.9923\right)$, respectively. The detection limit of $\mathrm{Cu}^{2+}$ was calculated to be $4.26 \mathrm{mg} \cdot \mathrm{L}^{-1}$ according to the ratio outlined in Eq. 3,

$3 \delta$ to $K$

where $\delta$ is the standard deviation of the blank experiments, and $K$ stands for the slope of the calibration curve (Sun et al. 2019).
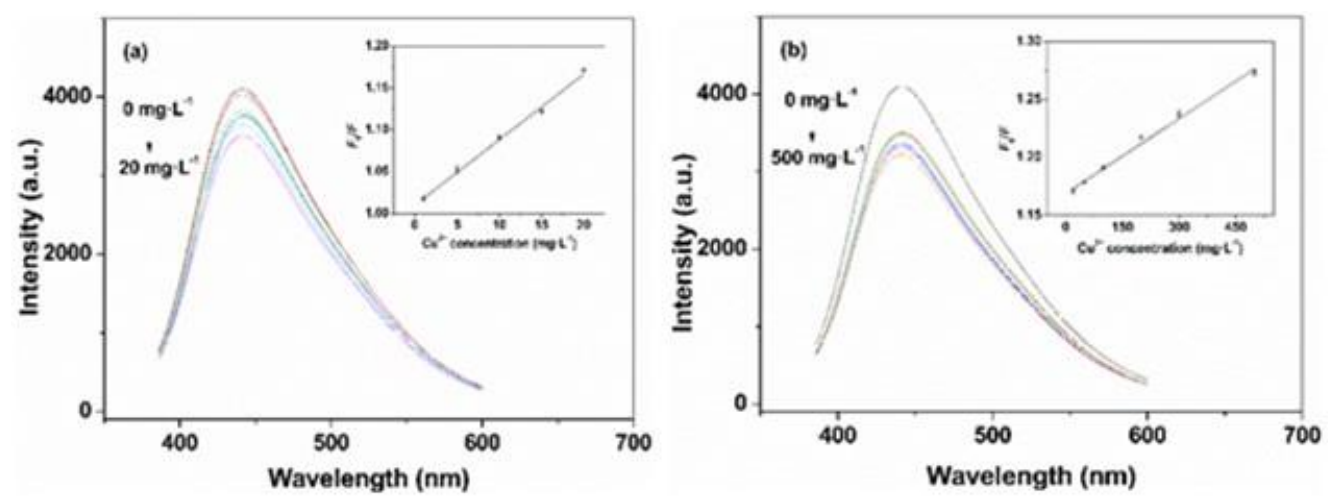

Fig. 7. (a) Fluorescence spectra of the N-CQDs (2 mL) in the presence of various concentrations of $\mathrm{Cd}^{2+}$ (from top to bottom: $0 \mathrm{mg} \cdot \mathrm{L}^{-1}, 1 \mathrm{mg} \cdot \mathrm{L}^{-1}, 5 \mathrm{mg} \cdot \mathrm{L}^{-1}, 10 \mathrm{mg} \cdot \mathrm{L}^{-1}, 15 \mathrm{mg} \cdot \mathrm{L}^{-1}$, and $20 \mathrm{mg} \cdot \mathrm{L}^{-1}$ ) in a PBS buffer solution at a pH of 6.7 under excitation at $365 \mathrm{~nm}$; and (b) the fluorescence spectra of the N-CQDs $\left(2 \mathrm{ml}\right.$ ) in the presence of various concentrations of $\mathrm{Cd}^{2+}$ (from top to bottom: $0 \mathrm{mg} \cdot \mathrm{L}^{-}$ ${ }^{1}, 20 \mathrm{mg} \cdot \mathrm{L}^{-1}, 50 \mathrm{mg} \cdot \mathrm{L}^{-1}, 100 \mathrm{mg} \cdot \mathrm{L}^{-1}, 200 \mathrm{mg} \cdot \mathrm{L}^{-1}, 300 \mathrm{mg} \cdot \mathrm{L}^{-1}$, and $\left.500 \mathrm{mg} \cdot \mathrm{L}^{-1}\right)$ in a PBS buffer solution at a pH of 6.7 under excitation at $365 \mathrm{~nm}$ (note: the inset images are the standard curve of the concentration of $\mathrm{Cd}^{2+}$ versus $\mathrm{F}_{0} / \mathrm{F}$ )

The selectivity was investigated by adding other metal ions $\left(500 \mathrm{mg} \cdot \mathrm{L}^{-1}\right)$, including $\mathrm{Zn}^{2+}, \mathrm{Co}^{2+}, \mathrm{Fe}^{2+}, \mathrm{Ni}^{2+}, \mathrm{Mg}^{2+}, \mathrm{Pb}^{2+}, \mathrm{Ag}^{+}, \mathrm{Mn}^{2+}, \mathrm{Cd}^{2+}$, and $\mathrm{K}^{+}$. The fluorescence intensities of the CQDs before and after the addition of metal ions were recorded at $365 \mathrm{~nm}$. The quenching changes with different metal ions are indicated in Fig. 8. Clearly, the fluorescence intensity of CQDs was further quenched in the presence of $\mathrm{Cu}^{2+}$ compared with the other metal ions. This may be because of the faster $\mathrm{Cu}^{2+}$ chelating kinetics and a higher affinity toward the oxygen-containing functional groups, e.g., - $\mathrm{COOH},-\mathrm{OH}$, and $\mathrm{NH}$, on the surface of CQDs compared with other ions (Hu et al. 2014; Gedda et al. 2016; $\mathrm{Xu}$ et al. 2021). Furthermore, paramagneticism makes $\mathrm{Cu}^{2+}$ more easily adsorbed on the surface of CQDs (Murugan et al. 2019). Thus, the fluorescence of CQDs may be quenched by $\mathrm{Cu}^{2+}$ via electron transfer, in which $\mathrm{Cu}^{2+}$ acts as an electron acceptor to block the electron-hole link (Hu et al. 2014; Wang et al. 2019). 


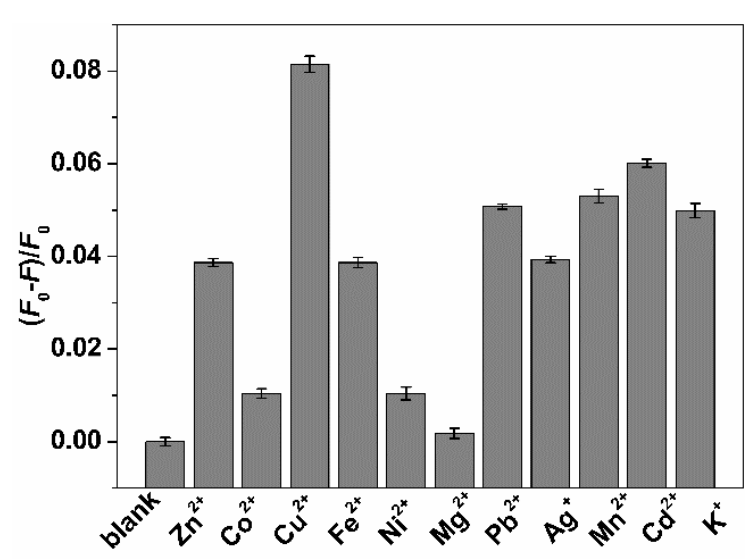

Fig. 8. Selectivity of the CQDs fluorescence probe toward $50 \mathrm{mg} / \mathrm{L} \mathrm{Cu}^{2+}$ over the coexisting cations under optimal conditions

\section{CONCLUSIONS}

1. Corn straw was successfully used as a raw material for hydrothermally producing carbon quantum dots (CQDs), which were used as a sensor for copper ions. Highresolution transmission electron microscopy (TEM) and X-ray diffraction (XRD) indicated that most of the CQDs particles were amorphous carbon with a lattice fringe of $0.208 \mathrm{~nm}$. In addition, Fourier transform infrared spectrometry (FTIR) and X-ray photoelectron spectrometry (XPS) showed that the surface of the CQDs was rich in oxygen-containing and nitrogen-containing functional groups.

2. The fluorescence of the CQDs can be quenched by $\mathrm{Cu}^{2+}$ because of charge transfer; the CQDs were then used as a sensing probe for $\mathrm{Cu}^{2+}$ detection. The linear relationships between the fluorescence change and the $\mathrm{Cu}^{2+}$ content $\left(1 \mathrm{mg} \cdot \mathrm{L}^{-1}\right.$ to $20 \mathrm{mg} \cdot \mathrm{L}^{-1}$ and 20 $\mathrm{mg} \cdot \mathrm{L}^{-1}$ to $\left.500 \mathrm{mg} \cdot \mathrm{L}^{-1}\right)$ were obtained, with coefficients of determination of 0.9960 and 0.9923 , respectively. The detection limit of $\mathrm{Cu}^{2+}$ was $4.26 \mathrm{mg} \cdot \mathrm{L}^{-1}$.

3. This work presents a simple method for the utilization of corn straw. The final CQDs exhibited excellent water dispersibility and chemical properties, which are promising for wide applications in environmental monitoring.

\section{ACKNOWLEDGMENTS}

This research was supported by the school-level Scientific Research Projects of Chaohu University (No. XLZ-201805 and No. XLZ-201806) and the Natural Science Research Project in Colleges and Universities of Anhui Province (No. KJ2019A0678).

\section{REFERENCES CITED}

Briscoe, J., Marinovic, A., Sevilla, M., Dunn, S., and Titirici, M. (2015). "Biomassderived carbon quantum dot sensitizers for solid-state nanostructured solar cells," Angewandte Chemie 54(15), 4463-4468. DOI: 10.1002/anie.201409290 
Cao, L., Sahu, S., Anilkumar, P., Bunker, C. E., Xu, J., Fernando, K. A. F., Wang, P., Guliants, E. A., Tackett II, K. N., and Sun, Y.-P. (2011). "Carbon nanoparticles as visible-light photocatalysts for efficient $\mathrm{CO}_{2}$ conversion and beyond," Journal of the American Chemical Society 133(13), 4754-4757. DOI: 10.1021/ja200804h

Feng, T., Ai, X., An, G., Yang, P., and Zhao, Y. (2016). "Charge-convertible carbon dots for imaging-guided drug delivery with enhanced in vivo cancer therapeutic efficiency," ACS Nano 10(4), 4410-4420. DOI: 10.1021/acsnano.6b00043

Gedda, G., Lee, C.-Y., Lin, Y.-C., and Wu, H. (2016). "Green synthesis of carbon dots from prawn shells for highly selective and sensitive detection of copper ions," Sensors and Actuators B: Chemical 224, 396-403. DOI: 10.1016/j.snb.2015.09.065

Hu, C., Yu, C., Li, M., Wang, X., Yang, J., Zhao, Z., Eychmüller, A., Sun, Y.-P., and Qiu, J. (2014). "Chemically tailoring coal to fluorescent carbon dots with tuned size and their capacity for Cu(II) detection," Small 10(23), 4926-4933. DOI: 10.1002/smll.201401328

Hu, Y., Chen, Z., Lai, F., and Li, J. (2019). "Biomass-codoped carbon dots: Efficient fluorescent probes for isocarbophos ultrasensitive detection and for living cells dualcolor imaging," Journal of Materials Science 54(11), 8627-8639. DOI: 10.1007/s10853-019-03494-9

Huang, K., He, Q., Sun, R., Fang, L., Song, H., Li, L., Li, Z., Tian, Y., Cui, H., and Zhang, J. (2019). "Preparation and application of carbon dots derived from cherry blossom flowers," Chemical Physics Letters 731, 1-5. DOI: 10.1016/j.cplett.2019.07.014

Jin, S., Chen, J., Mao, J., Yue, G., Han, Y., and Yu, X. (2017). “A novel superabsorbent from raw corn straw and poly(acrylic acid)," Polymer Composites 38(7), 1353-1362. DOI: $10.1002 / \mathrm{pc} .23701$

Jing, S., Zhao, Y., Sun, R.-C., Zhong, L., and Peng, X. (2019). "Facile and high-yield synthesis of carbon quantum dots from biomass-derived carbons at mild condition," ACS Sustainable Chemistry \& Engineering 7(8), 7833-7843. DOI: 10.1021/acssuschemeng.9b00027

Ke, C.-B., Lu, T.-L., and Chen, J.-L. (2018). "Capacitively coupled plasma discharge of ionic liquid solutions to synthesize carbon dots as fluorescent sensors," Nanomaterials 8(6), 372-383. DOI: 10.3390/nano8060372

Li, L.-S., Jiao, X. -Y., Zhang, Y., Cheng, C., Huang, K., and Xu, L. (2018). “Green synthesis of fluorescent carbon dots from Hongcaitai for selective detection of hypochlorite and mercuric ions and cell imaging," Sensors and Actuators B: Chemical 263, 426-435. DOI: 10.1016/j.snb.2018.02.141

Liu, Z., Jin, W., Wang, F., Li, T., Nie, J., Xiao, W., Zhang, Q., and Zhang, Y. (2019). "Ratiometric fluorescent sensing of $\mathrm{Pb}^{2+}$ and $\mathrm{Hg}^{2+}$ with two types of carbon dot nanohybrids synthesized from the same biomass," Sensors and Actuators B: Chemical 296, 1-8. DOI: 10.1016/j.snb.2019.126698

Medeiros, T. V.d., Manioudakis, J., Noun, F., Macairan, J.-R., Victoria, F., and Naccache, R. (2019). "Microwave-assisted synthesis of carbon dots and their applications," Journal of Materials Chemistry C 7(24), 7175-7195. DOI: 10.1039/C9TC01640F

Murugan, N., Prakash, M., Jayakumar, M., Sundaramurthy, A., and Sundramoorthy, A. K. (2019). "Green synthesis of fluorescent carbon quantum dots from Eleusine coracana and their application as a fluorescence 'turn-off' sensor probe for selective 
detection of $\mathrm{Cu}^{2+}$," Applied Surface Science 476, 468-480. DOI:

10.1016/j.apsusc.2019.01.090

Muthusankar, G., Sasikumar, R., Chen, S.-M., Gopu, G., Sengottuvelan, N., and Rwei, S.-P. (2018). "Electrochemical synthesis of nitrogen-doped carbon quantum dots decorated copper oxide for the sensitive and selective detection of non-steroidal antiinflammatory drug in berries," Journal of Colloid and Interface Science 523, 191200. DOI: $10.1016 /$ j.jcis.2018.03.095

Qi, H., Teng, M., Liu, M., Liu, S., Li, J., Yu, H., Teng, C., Huang, Z., Liu, H., Shao, Q., et al. (2019). "Biomass-derived nitrogen-doped carbon quantum dots: highly selective fluorescent probe for detecting $\mathrm{Fe}^{3+}$ ions and tetracyclines," Journal of Colloid and Interface Science 539, 332-341. DOI: 10.1016/j.jcis.2018.12.047

Qiao, Z.-A., Wang, Y., Gao, Y., Li, H., Dai, T., Liu, Y., and Huo, Q. (2010). "Commercially activated carbon as the source for producing multicolor photoluminescent carbon dots by chemical oxidation," Chemical Communications 46(46), 8812-8814. DOI: 10.1039/c0cc02724c

Ren, R., Zhang, Z., Zhao, P., Shi, J., Han, K., Yang, Z., Gao, D., and Bi, F. (2019). "Facile and one-step preparation carbon quantum dots from biomass residue and their applications as efficient surfactants," Journal of Dispersion Science and Technology 40(5), 627-633. DOI: 10.1080/01932691.2018.1475239

Ren, X., Zhang, F., Guo, B., Gao, N., and Zhang, X. (2019). "Synthesis of N-doped micropore carbon quantum dots with high quantum yield and dual-wavelength photoluminescence emission from biomass for cellular imaging," Nanomaterials 9(4), 1-13. DOI: 10.3390/nano9040495

Sidorov, A. I., Lebedev, V. F., Kobranova, A. A., and Nashchekin, A. V. (2018). "Formation of carbon quantum dots and nanodiamonds in laser ablation of a carbon film," Quantum Electronics 48(1), 45-48. DOI: 10.1070/QEL00000

Singh, A. K., Singh, V. K., Singh, M., Singh, P., Khadim, S. R., Singh, U., Koch, B., Hasan, S. H., and Ashtana, R. K. (2019). "One pot hydrothermal synthesis of fluorescent NP-carbon dots derived from Dunaliella salina biomass and its application in on-off sensing of $\mathrm{Hg}$ (II), Cr (VI) and live cell imaging," Journal of Photochemistry and Photobiology A: Chemistry 376, 63-72. DOI: 10.1016/j.jphotochem.2019.02.023

Su, R., Wang, D., Liu, M., Yan, J., Wang, J.-X., Zhan, Q., Pu, Y., Foster, N. R., and Chen, J.-F. (2018). "Subgram-scale synthesis of biomass waste-derived fluorescent carbon dots in subcritical water for bioimaging, sensing, and solid-state patterning," ACS Omega 3(10), 13211-13218. DOI: 10.1021/acsomega.8b01919

Sun, X., Liu, Y., Niu, N., and Chen, L. (2019). "Synthesis of molecularly imprinted fluorescent probe based on biomass-derived carbon quantum dots for detection of mesotrione," Analytical and Bioanalytical Chemistry 411(21), 5519-5530. DOI: 10.1007/s00216-019-01930-y

Wang, N., Li, X., Yang, X., Tian, Z., Bian, W., and Jia, W. (2019). "Nitrogen-doped carbon dots as a probe for the detection of $\mathrm{Cu}^{2+}$ and its cellular imaging," Journal of Chemical Research 43(11-12), 507-515. DOI: 10.1177/1747519819875046

Xie, Y., Cheng, D., Liu, X., and Han A. (2019). "Green hydrothermal synthesis of Ndoped carbon dots from biomass highland barley for the detection of $\mathrm{Hg}^{2+}$," Sensors 19(14), 1-10. DOI: 10.3390/s19143169 
Xu, J., Zhou, Y., Cheng, G., Dong, M., Liu, S., and Huang, C. (2015). "Carbon dots as a luminescence sensor for ultrasensitive detection of phosphate and their bioimaging properties," Luminescence 30, 411-415. DOI: 10.1002/bio. 2752

Xu, O., Wan, S., Zhang, Y., Li, J., and Zhu, X. (2021). "A unique dual-excitation carbon quantum dots: Facile synthesis and application as a dual-“on-off-on" fluorescent probe," Sensors and Actuators B: Chemical 340, 129904. DOI: 10.1016/j.snb.2021.129904

Yan, Z., Zhang, Z., and Chen, J. (2016). "Biomass-based carbon dots: synthesis and application in imatinib determination," Sensors and Actuators B: Chemical 225, 469473. DOI: $10.1016 /$ j.snb.2015.10.107

Yang, J., Chen, L., Jiang, Q., and Yue, X. (2019). “Optimized preparation of nitrogendoped carbon dots by response surface methodology and application in $\mathrm{Cd}^{2+}$ detection," Fullerenes, Nanotubes and Carbon Nanostructures 27(3), 233-239. DOI: 0.1080/1536383X.2018.1551211

Yang, Q., Duan, J., Yang, W., Li, X., Mo, J., Yang, P., and Tang, Q. (2018). "Nitrogendoped carbon quantum dots from biomass via simple one-pot method and exploration of their application," Applied Surface Science 434, 1079-1085. DOI: 10.1016/j.apsusc.2017.11.040

Yu, C., Xuan, T., Chen, Y., Zhao, Z., Sun, Z., and Li. H. (2015). “A facile, green synthesis of highly fluorescent carbon nanoparticles from oatmeal for cell imaging," Journal of Materials Chemistry C 3(37), 9514-9518. DOI: 10.1039/c5tc02057c

Yuan, H., Zhang, X., Li, D., and Chen, Y. (2018). "Strongly fluorescent carbon quantum dots from biomass tar as highly selective and sensitive probe for $\mathrm{Fe}^{3+}$ detection," Nano 13(4), 1-12. DOI: 10.1142/S1793292018500431

Yuan, M., Zhong, R., Gao, H., Li, W., Yun, X., Liu, J., Zhao, X., Zhao, G., and Zhang, F. (2015). "One-step, green, and economic synthesis of water-soluble photoluminescent carbon dots by hydrothermal treatment of wheat straw, and their bio-applications in labeling, imaging, and sensing," Applied Surface Science 355, 1136-1144. DOI: 10.1016/j.apsusc.2015.07.095

Zhu, L., Yin, Y., Wang, C.-F., and Chen, S. (2013). "Plant leaf-derived fluorescent carbon dots for sensing, patterning and coding," Journal of Materials Chemistry C 1(32), 4925-4932. DOI: 10.1039/c3tc30701h

Article submitted: August 2, 2021; Peer review completed: September 18, 2021; Revised version received and accepted: October 12, 2021; Published: December 1, 2021.

DOI: 10.15376/biores.17.1.604-615 